\title{
The Young Teachers Motivating Factors at Local Colleges
}

\author{
Xia Wang \\ International Education College of Kaifeng University \\ Kaifeng, China \\ E-mail: xiawang1996@126.com
}

\begin{abstract}
The young teacher is a valuable resource for universities; they have plasticity and development potential. Concern young teachers' motivations, emotions and needs, mobilize the enthusiasm of young teachers in colleges and universities; they are the fundamental of increase and develop the overall level of high education. In this paper, according to motivation theory, analysis young college teachers' professional and personal characteristics, and the questionnaire shows that the top three motivation factors for young teachers in colleges and universities are school development, salary, and spiritual life, and then make suggestions for motivate young teachers in the field of human resource.
\end{abstract}

Keywords-motivation; young teachers; human resource management

\section{INTRODUCTION}

21 st century is the time of knowledge economy, universities are knowledge-intensive organizations, and teachers who work in universities are the typical groups of knowledge workers. Among all the college teachers, young teachers have the most resilient, and also the potential of valuable human resources. The young teachers play important roles for colleges and universities. They are also the key part for the development quality and development speed of school. Economics and psychology fields have the largest and most representative researches about the motivation of young teachers. Economic researches mainly focus on teachers' pay system; psychology researches focus on the teachers' satisfaction and sense of accomplishment terms.

From the view of Economic, the studies mainly focus on the pay system. For example: Holmstrom and Milgrom (1991), Murphy (1992), Lazear (1997), etc. they analysis the efficiency of university teachers' pay system from the perspective of dynamic excitation; Konrad and Pfeffer (1990), Mejia and Balkin (1996), on the basis of empirical analysis, they find the determinants of university teachers' pay system. Salaries have always been aware, if treat performance as the teacher's commitment to schools and students, then the salary will as the result of performance appraisal system.

From the view of Psychology, HerZberg (1959) considers that it is a hygiene factor to prevent unsatisfactory, only motivation factors such as self-fulfillment are the key to satisfaction. Locke (1991) proposed aggregation model with "self-efficacy" concept. The model assumes that people's choice of targets affected by two separate factors: self-efficacy and performance motivations. Teachers has been able to work seriously in the salary-limited circumstances, the main reason is that their work bring them the sense of accomplishment and motivations.

In the domestic study of motivation factors, mainly focus on incentive factors, problems, strategy and recommendations. For example, Changxi Chen, Bingfu Lu (2011) suggested that college teachers' motivation effects by five factors: income factor, achievement factors, power factors, emotional factors and stress factors, and they analyzed these five aspects. Murong $\mathrm{He}$, Li Li (2010) argues that university teacher motivation exists common problems, including attention to the material needs and spiritual needs contempt and how to balance individual differences in teachers on the premise of fair.

In China, there are a lot of researches about teacher motivation "Table I". However, the literature about the motivation of local colleges and universities teachers is limited. In the Chinese academic websites (cnki.net), search the theme of "Local Universities" and "teacher motivation", there are total 139 results, then added "youth" to word frequency, only found 32 results.

TABLE I. COLLEGE TEACHER / YOUNG TEACHERS" CONTAINING WORD FREQUENCY "MOTIVATION" LITERATURE DisTRIBUTION TABLE

\begin{tabular}{|c|c|c|c|c|}
\hline Year & $1994-$ & $1999-$ & $2004-$ & $2009-$ \\
Period & 1998 & 2003 & 2008 & 2013 \\
\hline The number of & 90 & 327 & 1632 & 2807 \\
papers & $/ 22$ & 148 & $/ 115$ & $/ 267$ \\
\hline
\end{tabular}

Most of the studies neither consider the profession characteristics and personality characteristics of teachers, nor the young teacher's life cycle. Many research perspectives on the macro-level perspective of national universities, does not reflect the characteristics of local colleges and universities very well. Generally speaking, the reason is that local colleges and universities under the control of provinces and autonomous regions, most of them supported by the local financial department, compare with the national universities, they have different. 


\section{COllege Young Teachers' Professional CHARACTERISTICS}

\section{A. The Job Is Steady, but High Pressure of Survival and Development}

In China, teachers who work in colleges and universities belong to career preparation, therefore, teachers' income is relatively stable, generally, their wages were be made based on positions, titles, and teaching amount, their salary does not reflect a significant difference.

With the growing degree of public education by the universities, the number of young teachers under the age of 40 has more than 860,000 in China, accounting for nearly $65 \%$ of the total number of full-time university teachers in the country. This group is facing a lot of pressure, such as social pressure, economic pressure, life stress and competitive pressure.

Along with the reform of management mechanism in colleges and universities, it comes with position employment system, listing the teaching system elimination system, competition and other systems. This not only requires the young teachers have high education, but also complete certain teaching load and research tasks every semester. In order to accomplish job requirements as well as individual promoting needs, teachers in local colleges and universities should allocate their time and energy to deliver the goods.

\section{B. Teachers Have the High Social Status, and High Degree of Self-Identity}

Around the world, many countries believe that teachers as a hero of human cultural heritage, in Chinese society, teachers have a higher social status. For example, November 25, 2010 Eighth China civic scientific literacy survey results published in the prestigious science and technology careers; the top three are teachers $(55.10 \%)$, scientists $(44.02 \%)$, and doctors $(44.02 \%)$.

Contemporary university teachers all belong to a group which passing on professional knowledge and give education, guidance and influence to students on physical and mental. They aim to cultivate their students into person who can make contribution to the society. Therefore, academic knowledge and professional skills help university teachers established their professional positions. In the survey called "Which career you expect your children to do", teachers (50.81\%), doctors $(49.18 \%)$, and scientists $(35.95 \%)$ ranked in the top three, showing that teachers ' professional status is relatively high.

\section{Comparison of Theoretical Knowledge, Less Experience, the Title is Relatively Low}

Young teachers are the main strengths of the development of colleges and universities, play the important role of college prospect, development quality and development speed. Three functions of colleges and universities are teaching, researching and service to the community, improving the young teachers' teaching quality is not only the important content by colleges and universities, but also the goals and direction of young teachers' self-fulfillment. Scientific research requires extensive expertise and management capability of the subject, while young teachers have a certain professional qualities but lack of the necessary academic practice; young teachers engaged in the education works in colleges and universities, they have the professional enthusiasm, but lack a certain amount of experience in teaching and in declaring researches. They are inadequate on the professional prospects, understanding of direction, and also wide field of vision. Therefore, young teachers need to accept professional training in order to enhance and improve.

In Chinese universities, teachers are generally divided into four titles: assistant instructor, lecturer, associate professor, and professor. Most of the young teachers have higher academic qualifications and degrees but with a lower title, because the requirements of the professional title are getting higher and higher. According to the differences of university categories, there is no clear distinction between teaching universities and researching universities, so is on teacher 's assessing.

Assessment of professional titles in colleges and universities is based primarily on writing, thesis, project, teaching quality, and teaching amount. Obviously, for young teachers, it takes time to accumulate practice and experience that makes their titles are generally low in colleges and universities.

\section{College Young Teachers' Personality CHARACTERISTICS}

\section{A. Strong Achievement Motivation}

Psychologists believe that people in the 25 years old to 45 years old is the golden time for perception, memory, judgment, analysis, action and reaction capabilities. Young teachers in the colleges and universities are all belong to golden period with the advantage of high level of education, new professional knowledge, active thinking, and willing to innovation. They are ambition on their careers, performance on energetic, trying to innovation and development in their own professional fields and have strong achievement motivations.

\section{B. Strong Self-Consciousness}

Currently, most of the young teachers in the colleges and universities of China were born in the 1970s and 1980s, in the terms of China's economic system; they experienced a great transition from the socialist planned economy to market economy. With the rapid advances in technology, they experienced the impact of the wave of the Internet. External environment makes the young teachers have global, democratic and progressive way of thinking. In state politics, they lived in an age of peace with little turmoil. The improvement of material life and higher requirements of spiritual life give young teachers a distinctive personality and strong sense of self.

\section{Control Sentiment Is Not Strong}

A Yong person has limited social experience, when he is facing pressures from the community, from work and family, may occur some emotional issues. For young teachers in the colleges and universities, they always have limited working experience with low salary and the title is relatively low, it is difficult to apply for research funds. At the same time, they live 
in the stage of massive questions such as getting married, buying a home, buying a car, children's education, supporting the elderly and so on, therefore, some young teachers have to take various part time jobs to support family financial.

\section{Young Teachers motivating Factors - A CASE}

Motivation is often divided into stimulation and encouragement, in particular to the stimulation of human's intrinsic motivation and the progress of encouraging people to take conscious actions toward to the goals that are accepted by institutions. This conception includes three meanings: first, motivation is a mental process; second, motivation is a conscious behavior of human's; third, motivation serves for organizational goals. Malause's hierarchy of needs theory and Herzberg's two-factor theories are the key theory of the content activation theory.

Maslows "hierarchy of needs theory" divided human needs into physiological needs, safety needs, social needs, esteem needs and self-actualization needs. The core theory in Maslows' is: first, physiological needs and security needs are lower level needs, social needs, esteem needs and selfactualization needs are higher needs; second, human's behavior is drive by their needs, so the unmet needs can make an effect on encouraging; third, people may exist several needs, the highest strength need is called the dominant need.

Herzberg's "two-factor theory" considered that the opposite of satisfaction is dissatisfaction (these factors are called motivators); the opposite of dissatisfaction is no dissatisfaction (these factors are called hygiene factors). The core of the theory is: first, motivators is associated with job satisfaction and motivation, and hygiene factor is associated with job dissatisfaction; second, when hygiene factor fully improves, people have no feeling of dissatisfaction; when motivators has no improvement, people feel no satisfaction.

Based on the theory above, designing a research focus on the young teachers in colleges and universities of Kaifeng City, providing 2760 forms of questionnaire survey and reclaim 1819 of them and 1665 validated questionnaires. The results of investigation as follow :

- The proportion of young female teachers is $40 \%$ higher than male teachers, which means more women prefer to be a teacher than the number of men.

- The education level of young teachers is spindle-shaped, which means majorities of them is graduated from college with masters or bachelor degrees but less higher degree like phd or lower degree.

- Mainly of young teachers remain in intermediate title, less in junior and senior positions; it is not contradict with young teachers' work seniority and scientific productivity.

- Young teachers' work seniority is below 15 years, which is relatively low; it is associated with the sample selection.

- Academic training is the most popular training which young teachers want to received, followed by teaching training, less young teachers focus on mental health education and political training.

- Young teachers are generally lying on the satisfied stage for their salaries. Higher degree of satisfaction on spiritual needs than material needs. They are being hopeful about the future.

\section{OPTIMIZATION STRATEGY OF HUMAN RESOURCES MANAGEMENT}

\section{A. Promotion Channel Is Diversified}

For young teachers in the colleges and universities, it is unattractive to get promotion through standard hierarchy ladder, even has potential negative factors. Getting promote is the key point for most of young teachers, it not only means higher salary but also a mark of play an important role in the college. It means make more contribution for the organization and mental stimulation for themselves. Therefore, the multichannel promotion system should be established in the colleges and universities, bring young teachers' potential into full play. The diversification of promotion channels reflected educational flexibility and innovative capabilities in the colleges and universities.

\section{B. Job Enlargement, Job Enrichment}

Job enlargements of young teachers have access to engage variety of work, and make them understand and experience other people's work; it is not only a challenge of personal skills but also take advantage to make communication between teachers. With the development society and economic, teaching and doing research are not enough for teachers, they should assume the responsibility of commitment to our communities and make contribution to our society, such as hold the post of tutors serve in the school-enterprise cooperation or attachment in enterprise training, attend the techniques training, lead students to take part in professional competitions to hone their skills and broaden their horizons, academic activities across schools or across departments, and so on. Diversification young teachers' skills and make job enlargement and enrichment.

\section{The Motivation-Oriented Training and Development}

Canadian scholars Heriot believes (2000), "knowledge and learning, obviously do not learn, there is no knowledge, knowledge is the combination of technology and experience in a particular area of the carrier; learning is to obtain knowledge, and the ability to combine them used to work."

In the 21st century, with the continuous innovation and development of Internet technologies, the training methods are also having great changes stealthily. Although traditional training methods are still able to exert the advantage, but the electronic computer and Internet training, video training and learning portal appear more common in colleges and universities.

Training is not only allow teachers to do their own work better, but also helps adapt to the new environment of knowledge, economic and technological. For example, faculty 
diversity in international education and the increase the number of Sino-foreign education programs, teachers are to be able to communicate with foreign teachers on various aspects of professional, humanities and science in a cross-cultural environment.

Through the entire career of young teachers in the colleges and universities, they should treat themselves like batteries and realizing the process of "charging" and "discharging". It is the concept of lifelong learning that improves teachers' ability to adapt to the changing environment as well as further enhancing teachers' learning abilities and teaching qualities.

\section{Stress Management}

Motivations are often divided into material motivations and mental stimulations. Material motivations generally refer to money. Mental stimulations refer to satisfaction, sense of achievement, happiness, the rights and positions, insurance and welfare. Appropriate motivations will produce good results, but improper motivations will bring pressure.

Pressure (stress) is a personal desire to face with their own goals related opportunities, limitations and requirements; the results feel uncertainty arising from the dynamic situation. It is an oppressive condition of physical or mental or social or economic distress. How to deal with stress is the problem everyone will face and the young teachers are no exception. On teacher performance, the effect of pressure can be positive and also can be negative. Therefore, the organization should dealing with motivations and pressure combined with human resource management practices; find ways to increase young teachers' personal qualities from the dynamic internal and external environment.

\section{CONCLUSION}

The young teachers motivating factors are: development of the school, personal income, and spiritual life.

According to motivation theory, the development of colleges and universities is a high level of needs, it belongs to "motivation factor" in two-factor theory. Personal income is a low level of needs, it belongs to "hygiene factor" in two-factor theory. Spiritual life is a high level of needs, it belongs to the "motivation factor" in two-factor theory.

In other words, the young teachers' primary focus is on the needs of the future and the development of the school, because the school is an institution, on which young teachers' personal survival and development is dependent. Next, in modern society, college and university young teachers' salary level is a pressing problem that is directly related to their survival and development. Finally, the demand for the spiritual life of young teachers is also particularly important, because it is closely linked with the teachers' career, personality and characteristic.

\section{REFERENCES}

[1] Yanbo Liu,University teachers need to study the characteristics and Motivation [J],China University of Geosciences (Social Sciences),2004 (04).
[2] Shiqing Ding,University teachers based on the theory of human capital motivation mechanism[J],Yunnan University of Finance and Economics, 2007 (4).

[3] Xia Wang,Enterprise knowledge employees motivation mechanism[J], Managers,2012 (2).

[4] NaYun,Local colleges teachers' job satisfaction factors - based on the investigation of eight college in Henan Province [J],educational theory and practice,2010 (33).

[5] Yuhong Li ,Jin Guan,Autumn teacher satisfaction of contingency analysis-local universities motivation mode[J],Social Science of Jiamusi University,2010 (05). 